\title{
Biosynthesis of silver nanoparticles using pennyroyal water extract as a green route
}

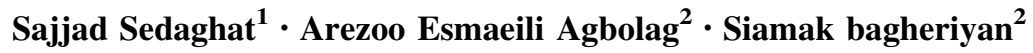

Received: 21 June 2015/Accepted: 14 September 2015/Published online: 24 November 2015

(C) The Author(s) 2015. This article is published with open access at Springerlink.com

\begin{abstract}
Synthesis of silver nanoparticles (Ag NPs) using water extract of pennyroyal is carried out successfully at ambient temperature. The obtained Ag NPs were characterized, using different methods including ultraviolet-visible spectroscopy, powder X-ray diffraction, scanning electron microscopy and transmission electron microscopy (TEM). TEM study showed that mean diameter and standard deviation for the formation of silver nanoparticles were $19.14 \pm 9.791 \mathrm{~nm}$.
\end{abstract}

Keywords Biosynthesis - Silver nanoparticles ·

Pennyroyal · Green route

\section{Introduction}

Silver nanoparticles (Ag NPs) are the most applicable and interesting NPs between researchers. Nanomaterials have interested a lot of attentions due to the remarkable difference in structural and physical properties of atoms and molecules [1]. Nanomaterials can improve the human life and its environment. Several physical and chemical processes [2] for synthesis of metal nanoparticles have been investigated for real life such as medicine [3], catalysis [4] and detection of DNA hybridization [5]. Ag NPs can be synthesized using physical and chemical methods such as ultrasonic fields, UV irradiation and photochemical

Sajjad Sedaghat

sajjadsedaghat@yahoo.com

1 Department of Chemistry, Faculty of Science, Malard Branch, Islamic Azad University, Tehran, Iran

2 Department of Chemistry, Faculty of Science, Shahryar Branch, Islamic Azad University, Tehran, Iran reduction [5], but the use of toxic chemicals as reducing agents in many of these routes is potentially dangerous to the environment and biological systems [6]. Green routes for synthesis of Ag NPs nanoparticles by a biological process using plant extract containing phytochemical agents have attracted considerable interest in recent years. Such green process can lead the formation of nanoparticles to more biocompatible, environmental benign and costeffective products [7]. On the basis of the available literature, we hypothesize that pennyroyal could be used in the synthesis of Ag NPs. The nanoparticles were characterized by UV-visible spectroscopy, XRD and TEM analysis.

\section{Materials and methods}

\section{Preparing the water extract of pennyroyal}

Green leaves of pennyroyal were collected in September 2014, from Sabalan region of Iran. $\mathrm{AgNO}_{3}(99.80 \%$ ) was purchased from Merck. All aqueous solutions were prepared using double-distilled water. Pennyroyal green leaves were washed and dried in shade during a week. The dried leaves were then ground into powder and kept at $25^{\circ} \mathrm{C}$ until further analyses. The ground of pennyroyal leaves $(10 \mathrm{~g})$ were extracted with double-distilled water (ratio 1:10 w/v), with boiling the mixture for $10 \mathrm{~min}$ in a water bath. The mixture was then filtered and centrifuged at $4000 \mathrm{rpm}$ for $10 \mathrm{~min}$ to remove any proteins from the extract. The extract was then kept in a dark bottle at $25^{\circ} \mathrm{C}$ until for 1 week.

\section{Synthesis of silver nanoparticles}

A solution containing $100 \mathrm{ml}$ of $\mathrm{AgNO}_{3}(0.01 \mathrm{M})$ and $20 \mathrm{~mL}$ of the water extract of pennyroyal was mixed at 
Fig. 1 UV-Vis absorption spectra of Ag/pennyroyal emulsion after 1 day

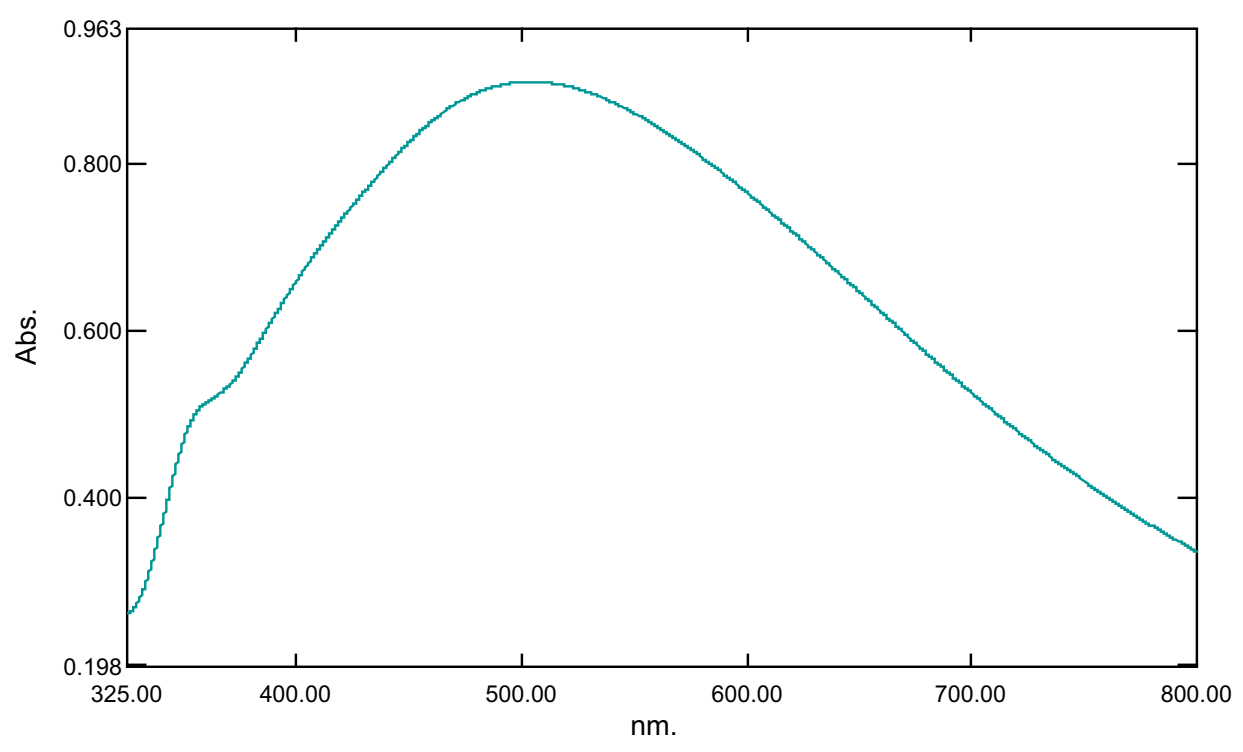

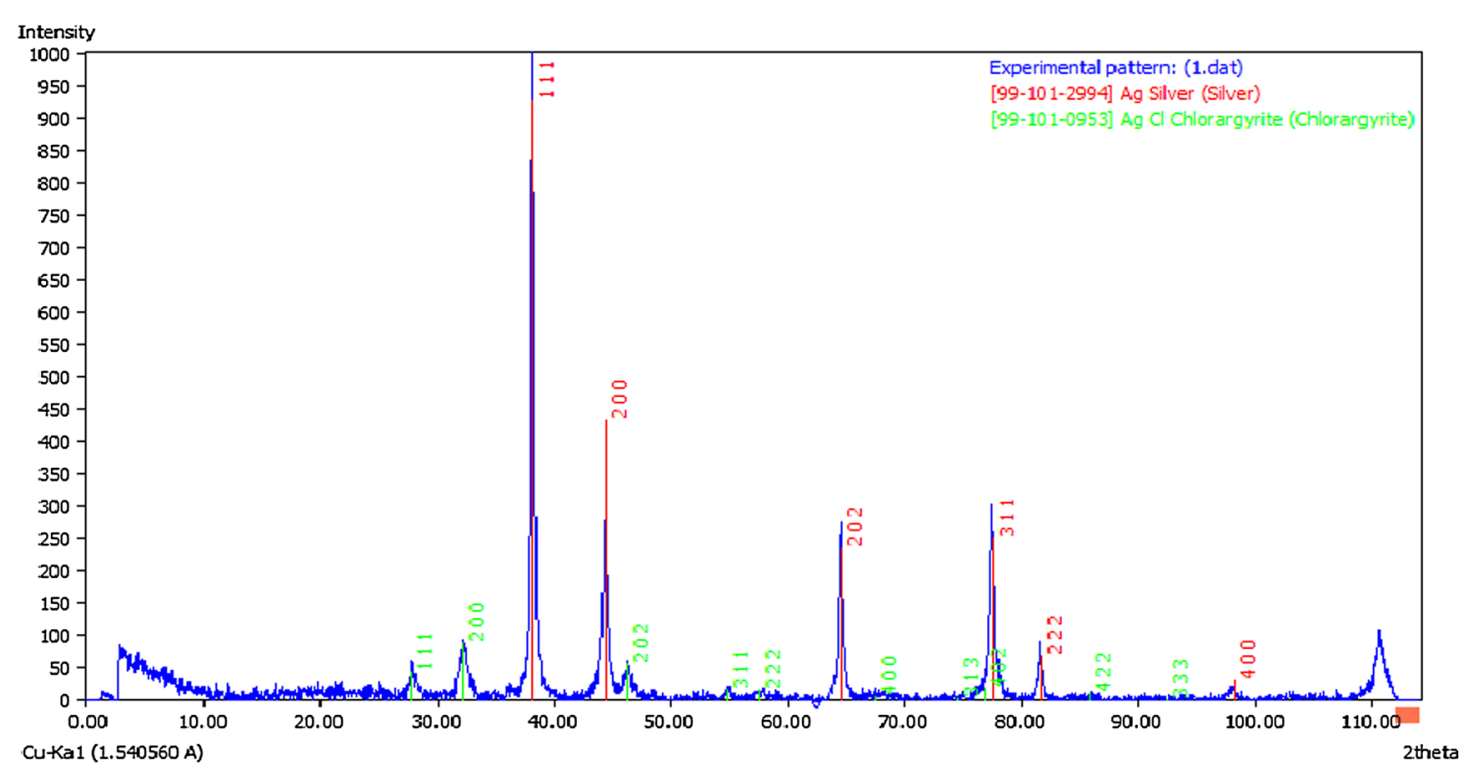

Fig. 2 XRD patterns of silver NPs synthesized by pennyroyal water extract

room temperature $\left(25^{\circ} \mathrm{C}\right)$ for 1 day with vigorous stirring. Silver nanoparticles were gradually obtained during the reaction. Then, the solution was filtered with membrane filter paper $(0.2 \mu \mathrm{m})$ and was washed by double-distilled water to remove residues. Ag NPs were dried in an oven at $80{ }^{\circ} \mathrm{C}$ for $24 \mathrm{~h}$ and were collected in an inert atmosphere for further evaluations.

\section{Characterization of silver nanoparticles}

The morphology of the Ag NPs was studied using the Xray diffraction (XRD, Inel, EQUINX 3000). The TEM observations were carried out using (TEM, Zeiss, EM 10 C-100 kV) electron microscope, and the SEM was

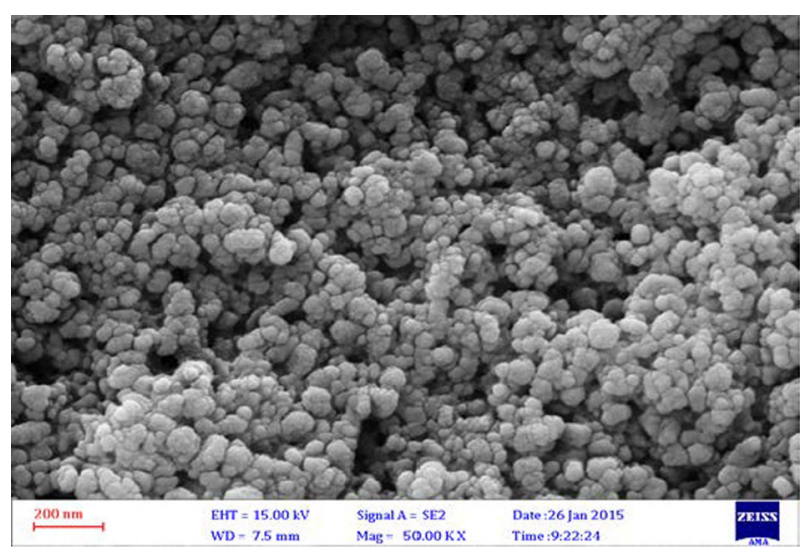

Fig. 3 SEM image of Ag/pennyroyal NPs 


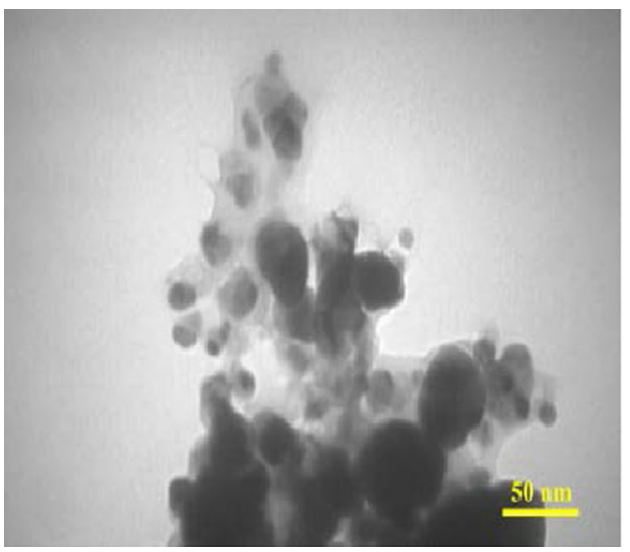

Fig. 4 TEM image and corresponding size of Ag/pennyroyal

performed using a Zeiss $\sum$ IGMA VP instrument to study the morphology of Ag NPs. The UV-visible spectra were recorded over the 200-800 $\mathrm{nm}$ rang with an UV Bio-TEK UV-visible spectrophotometer.

\section{Results and discussions}

The UV-Vis absorption spectra recorded for Ag NPs solution and suspension in water are shown in Fig. 1. The maximum absorption at $490 \mathrm{~nm}$ can be attributed to the plasma resonance absorption of silver particles.

The X-ray diffraction patterns recorded for silver nanoparticles are shown in Fig. 2. The X-ray patterns revealed diffraction peaks at $2 \theta$ of about 38.24, 44.42, $64.44,77.44$ and 81.25 which could be attributed to the 111 , 200, 220, 311 and 222 orientations, respectively, which are matched to the face-centered cubic (fcc) phase of $\mathrm{Ag}^{\circ}$.

SEM images of silver nanoparticles, synthesized by this method, are shown in Fig. 3. SEM images of silver nanoparticles confirm the existence of small and uniformly spherical nanoparticles. In Fig. 3, the uniform nanoparticles of $\mathrm{Ag}^{\circ}$ can be seen, also the formation of nanoparticles and stabilization with pennyroyal water extract that is the major deal for prevention of agglomeration of Ag nanoparticles. The average particle size of Ag-NPs synthesized using pennyroyal water extract was about $19.14 \pm 9.791 \mathrm{~nm}$.

TEM image of Ag NPs and their size distribution are shown in Fig. 4. The result showed narrow particle size distributions. Moreover, the mean diameter and standard deviation of silver nanoparticles is $19.14 \pm 9.791 \mathrm{~nm}$.

\section{Conclusions}

It can be concluded that silver nanoparticles were synthesized with an average size of $19.14 \pm 9.791 \mathrm{~nm}$ and spherical in shape, using the water extract of pennyroyal at room temperature. Silver nanoparticles were characterized by UV-visible, SEM, TEM and XRD. The green synthesis of nanoparticles is an eco-friendly method because of the usage of natural products.

Acknowledgments The authors are grateful to the Islamic Azad University, for their help in this research.

Open Access This article is distributed under the terms of the Creative Commons Attribution 4.0 International License (http://crea tivecommons.org/licenses/by/4.0/), which permits unrestricted use, distribution, and reproduction in any medium, provided you give appropriate credit to the original author(s) and the source, provide a link to the Creative Commons license, and indicate if changes were made.

\section{References}

1. Darroudi, M., Ahmad, M.B., Zamiri, R., Zak, A.K., Abdullah, A.H., Ibrahim, N.A.: Time-dependent effect in green synthesis of silver. Int. J. Nanomed. 6, 677-681 (2011)

2. Brocchi, E.A., Motta., M.S., Solorzano, I.G., Jena, P.K., Moura, F.J.: Alternative chemicalbased synthesis routes and characterization of nano-scale particles. Mater. Sci. Eng. B 112, 200-205 (2004)

3. Sanvicens, N., Marco, M.P.: Multifunctional nanoparticlesproperties and prospects for their use in human medicine. Trends Biotechnol. 26, 425-433 (2008)

4. Johnson, B.F.G.: From clusters to nanoparticles and catalysis. Coord. Chem. Rev. 190-92, 1269-1285 (1999)

5. Peng, H., Soeller, C., Cannell, M.B., Bowmaker, G.A., Cooney, R.P., Sejdic, J.T.: Electrochemical detection of DNA hybridization amplified by nanoparticles. Biosens. Bioelectr. 21, 1727-1736 (2006)

6. Reddy, N.J., Vali, D.N., Rani, M., Rani, S.S.: Evaluation of antioxidant, antibacterial and cytotoxic effects of green synthesized silver nanoparticles by Piper longum fruit. Mater. Sci. Eng. C 34, 115-122 (2014)

7. Mittal, A.K., Chisti, Y., Banerjee, U.C.: Synthesis of metallic nanoparticles using plant extracts. Biotechnol. Adv. 31, 346-356 (2013) 